Supporting Information for

\title{
Hot-Hole-Induced Molecular Scissoring: A Case Study of Plasmon-Driven Decarboxylation of Aromatic Carboxylates
}

Qingfeng Zhang, ${ }^{\dagger}$ Kexun Chen, and Hui Wang*

Department of Chemistry and Biochemistry, University of South Carolina, 631 Sumter Street, Columbia, South Carolina 29208, United States

${ }^{*}$ To whom correspondence should be addressed.

Email:wang344@mailbox.sc.edu (H.Wang);Phone: 803-777-2203; Fax:803-777-9521

Present Address:

${ }^{\dagger}$ College of Chemistry and Molecular Sciences, Wuhan University, Wuhan, Hubei 430072, China 


\section{S1. Additional Experimental Details}

\section{S1.1 Chemicals and Materials}

Ethylene glycol (EG) was obtained from VWR International. Polyvinylpyrrolidone (PVP58, MW = $\sim 58,000)$, thiophenol $\left(\mathrm{C}_{6} \mathrm{H}_{6} \mathrm{~S}\right.$, TP, 99+\%), 4-mercaptobenzoic acid $\left(\mathrm{C}_{7} \mathrm{H}_{6} \mathrm{O}_{2} \mathrm{~S}, 4-\mathrm{MBA}, 99 \%\right)$, and 2mercaptobenzoic acid $\left(\mathrm{C}_{7} \mathrm{H}_{6} \mathrm{O}_{2} \mathrm{~S}, 2-\mathrm{MBA}, 97 \%\right)$ were purchased from Alfa Aesar. Silver trifluoroacetate $\left(\mathrm{CF}_{3} \mathrm{COOAg}, \geq 99.99 \%\right)$, sodium hydrosulfide hydrate $\left(\mathrm{NaHS} \cdot \mathrm{xH}_{2} \mathrm{O}\right)$, hydrochloric acid $(\mathrm{HCl}, 37 \%$ in water), sodium hydroxide solution $(\mathrm{NaOH}, 50 \%$ in water), poly(diallyl dimethylammonium chloride) (PDDA, 20 wt. $\%$ in water, MW = 200,000-350,000), and poly-4-vinylpyridine (MW $=\sim 60,000$ ) were purchased from Sigma-Aldrich. Carboxylate-functionalized $\mathrm{SiO}_{2}$ beads with an average diameter of $\sim 1 \mu \mathrm{m}$ were purchased from Bangs Laboratories, Inc.. Hydrogen peroxide $\left(\mathrm{H}_{2} \mathrm{O}_{2}, 30 \%\right)$, sulfuric acid $\left(\mathrm{H}_{2} \mathrm{SO}_{4}\right.$, $96.10 \%$ ), and ethanol (200 proof) were purchased from Fisher Scientific. Acetone was purchased from Honeywell. All reagents were used as received without further purification. Ultrapure water (18.2 M $\Omega$ resistivity, Barnstead EasyPure II 7138) was used for all experiments. Silicon wafers were purchased from University Wafers.

\section{S1.2 Synthesis of Ag Nanocubes}

Ag nanocubes were synthesized following a protocol developed by Xia and coworkers. ${ }^{1}$ In a typical procedure, $20 \mathrm{~mL}$ of EG was added into a $100 \mathrm{~mL}$ flask and preheated for 40 min under magnetic stir in a temperature-controlled oil bath set at $150{ }^{\circ} \mathrm{C}$. A series of reagents dissolved in EG were sequentially added into the flask using a pipette. Specifically, $0.25 \mathrm{~mL}$ of NaHS solution $(3 \mathrm{mM})$ was first added. After $2 \mathrm{~min}$, $1.5 \mathrm{~mL}$ of $\mathrm{HCl}(3 \mathrm{mM})$ was added, followed by the addition of $5.0 \mathrm{~mL}$ of PVP58 $(150 \mathrm{mg} / \mathrm{mL})$. After another $2 \mathrm{~min}, 1.5 \mathrm{~mL}$ of $\mathrm{CF}_{3} \mathrm{COOAg}$ solution $(282 \mathrm{mM})$ was added. The flask was capped with a glass stopper during the reactions except when the chemical reagents were added. Ag nanocubes with edge-lengths of 36 $\pm 0.79 \mathrm{~nm}$ were obtained by quenching the reaction with an ice-water bath when the suspension had reached a brown color with a well-defined localized plasmon resonance peak at around $415 \mathrm{~nm}$. After centrifugation and wash with acetone once and water twice, the Ag nanocubes were redispersed in $2 \mathrm{~mL}$ of EG as colloidal suspensions for future use.

\section{S1.3 Synthesis of $\mathrm{SiO}_{2} @ A g$ Nanocubes Suprananoparticles $\left(\mathrm{SiO}_{2} @ \mathrm{Ag} \mathrm{SNPs}\right)$}

The surfaces of the $\mathrm{SiO}_{2}$ beads were densely decorated with Ag nanocubes to form $\mathrm{SiO}_{2} @ \mathrm{Ag} \mathrm{SNPs}$ following a previously reported protocol. ${ }^{2,3}$ Briefly, a colloidal suspension of carboxylate-functionalized $\mathrm{SiO}_{2}$ beads ( $9.8 \mathrm{mg} \mathrm{mL}^{-1}$, suspended in water) was added to $1 \mathrm{~mL}$ of aqueous PDDA solution (1\%). After sonication for $30 \mathrm{~min}$, the PDDA-functionalized $\mathrm{SiO}_{2}$ beads were collected by centrifugation and washed three times with pure water. $0.1 \mathrm{~mL}$ of the as-synthesized $\mathrm{Ag}$ nanocubes was incubated with the colloidal PDDA-functionalized $\mathrm{SiO}_{2}$ beads under magnetic stir at room temperature for $1 \mathrm{~h}$. The product was centrifuged and then incubated with Ag nanocubes again to increase the surface coverage of Ag nanocubes. This incubation-centrifugation process was repeated five times to achieve a saturated coverage of $\mathrm{Ag}$ nanocubes on the surfaces of the PDDA-functionalized $\mathrm{SiO}_{2}$ beads and the final product was redispersed in water for future use. 


\section{S1.4 Structural Characterizations of Nanoparticles}

Transmission electron microscopy (TEM) images were obtained using a Hitachi H-8000 transmission electron microscope operated at an accelerating voltage of $200 \mathrm{kV}$. All samples for TEM measurements were dispersed in water and drop-dried on 300 mesh Formvar/carbon-coated $\mathrm{Cu}$ grids. The morphologies of the $\mathrm{SiO}_{2}$ beads and the $\mathrm{SiO}_{2} @ \mathrm{Ag} \mathrm{SNPs}$ on silicon substrates were also characterized by scanning electron microscopy (SEM) using a Zeiss Ultraplus thermal field emission scanning electron microscope. The optical extinction spectra of the nanoparticles were measured on aqueous colloidal suspensions at room temperature using a Beckman Coulter Du 640 spectrophotometer. Dark-field and bright-field microscopy images were

obtained using an Olympus BX51 optical microscope, which was integrated with a BaySpec Nomadic ${ }^{T M}$ confocal Raman microscope.

\section{S1.5 Immobilization of Isolated $\mathrm{SiO}_{2} @ \mathrm{Ag}$ SNPs on Si Substrates}

The SERS measurements were performed on individual 4-MAB or 2-MBA-coated $\mathrm{SiO}_{2} @ \mathrm{Ag} \mathrm{SNPs}$, which were immobilized on poly-4-vinylpyridine-functionalized silicon substrates as a sub-monolayer film of isolated particles. ${ }^{4-6}$ In a typical procedure, silicon substrates were cleaned in a piranha solution $\left(\mathrm{H}_{2} \mathrm{SO}_{4}: \mathrm{H}_{2} \mathrm{O}_{2}, 7: 3\right.$ volume ratio) for $15 \mathrm{~min}$, and then immersed in an ethanolic solution of $1 \mathrm{wt}$. \% poly-4vinylpyridine for $24 \mathrm{~h}$. The silicon substrates were then thoroughly rinsed with ethanol and dried in a $\mathrm{N}_{2}$ gas flow before use. The $\mathrm{SiO}_{2} @ \mathrm{Ag}$ SNPs were incubated with an ethanolic solution of $500 \mu \mathrm{M}$ 4-MBA or 2MBA for $4 \mathrm{~h}$, and then washed with ethanol and redispersed in water. The poly-4-vinylpyridinefunctionalized silicon substrates were immersed in an aqueous suspension of 4-MBA- or 2-MBA-coated $\mathrm{SiO}_{2} @ \mathrm{Ag}$ NC SNPs for $1 \mathrm{~h}$. The silicon substrates were thoroughly rinsed with ethanol and dried with $\mathrm{N}_{2}$ gas after they were removed from the colloidal suspensions of 4-MBA- or 2-MBA-coated SiO ${ }_{2} @ A g$ SNPs. 


\section{S2. Additional Figures}
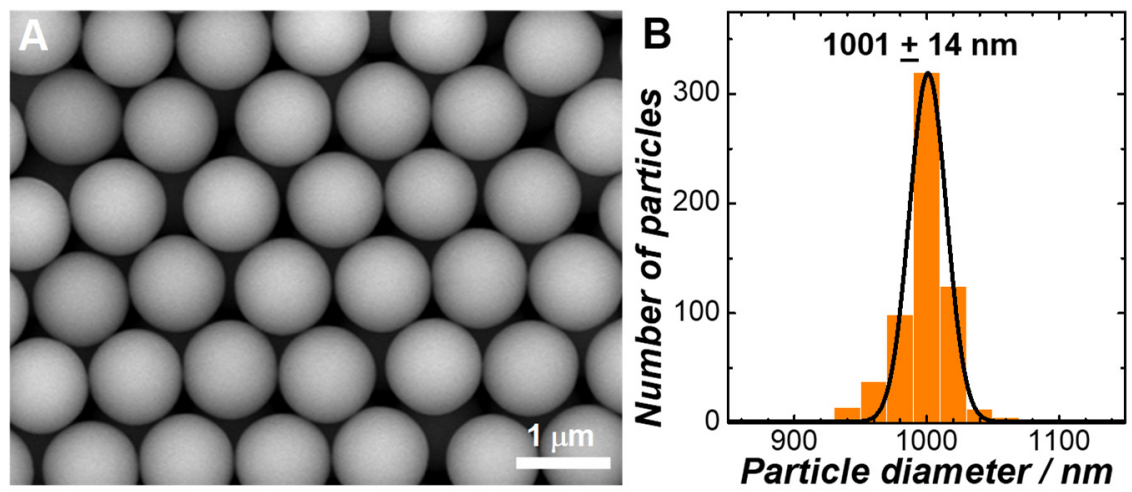

Figure S1. (A) SEM image and (B) size distribution of carboxylate-functionalized $\mathrm{SiO}_{2}$ beads. The size distribution histograms were fitted with a Gaussian distribution function and the fitting results were shown as the black curve in panel B. The mean particle sizes and standard deviations were also labeled in panel B.
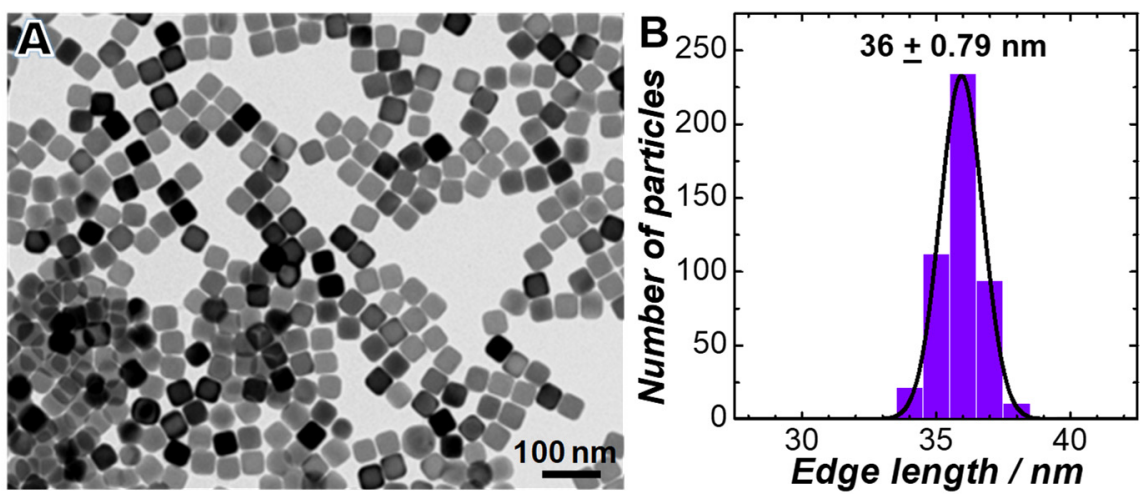

Figure S2. (A) TEM image and (B) size distribution of Ag nanocubes. The size distribution histograms were fitted with a Gaussian distribution function and the fitting results were shown as the black curve in panel B. The mean particle sizes and standard deviations were also labeled in panel B.

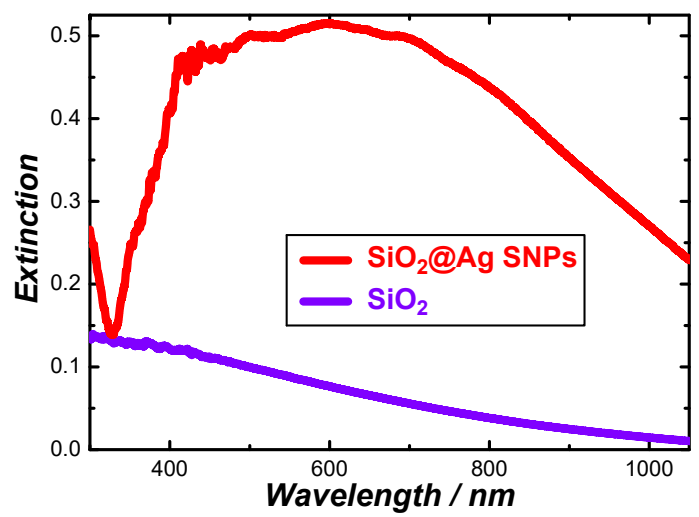

Figure S3. Optical extinction spectra of colloidal carboxylate-functionalized $\mathrm{SiO}_{2}$ beads and $\mathrm{SiO}_{2} @ \mathrm{Ag}$ SNPs dispersed in water. 

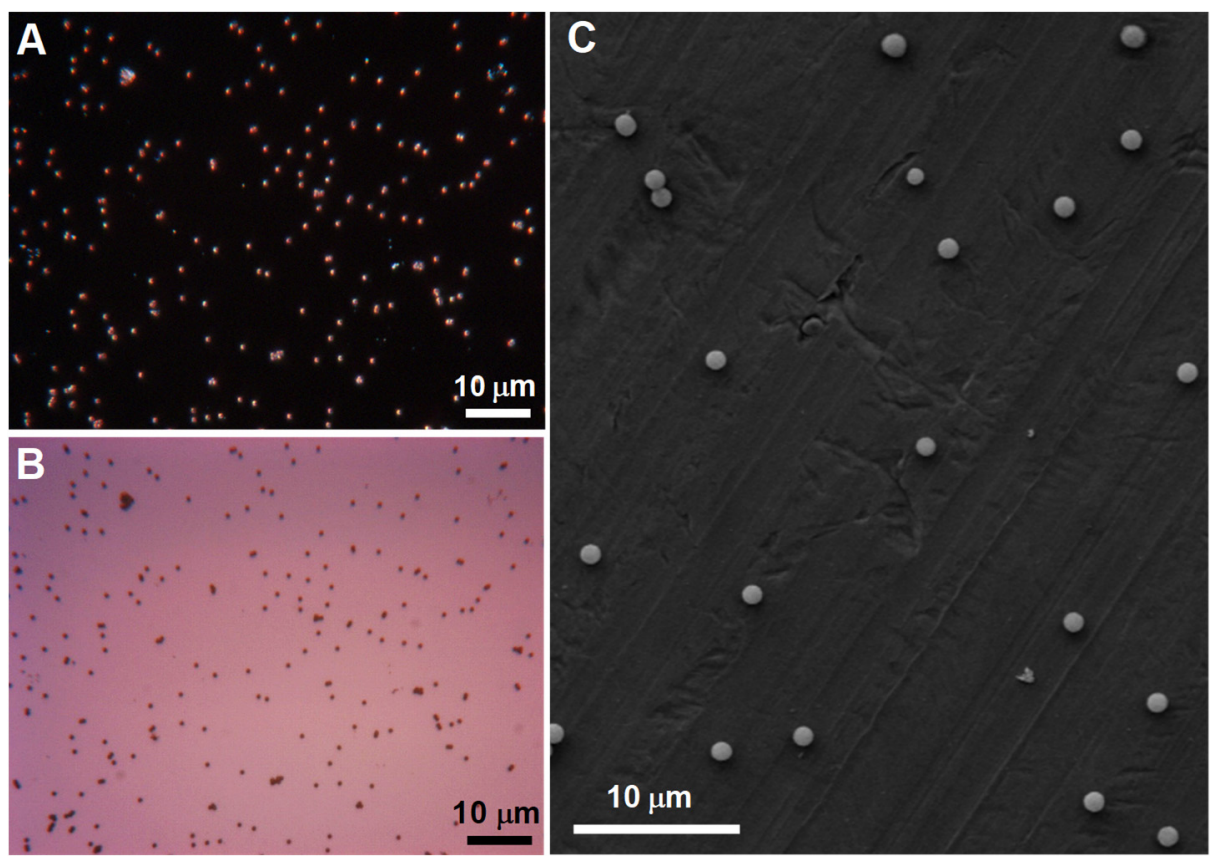

Figure S4. (A) Dark-field optical image, (B) bright-field optical image, and (C) SEM image of isolated $\mathrm{SiO}_{2} @ \mathrm{Ag} \mathrm{SNPs}$ on a poly-4-vinylpyridine-functionalized silicon substrate.
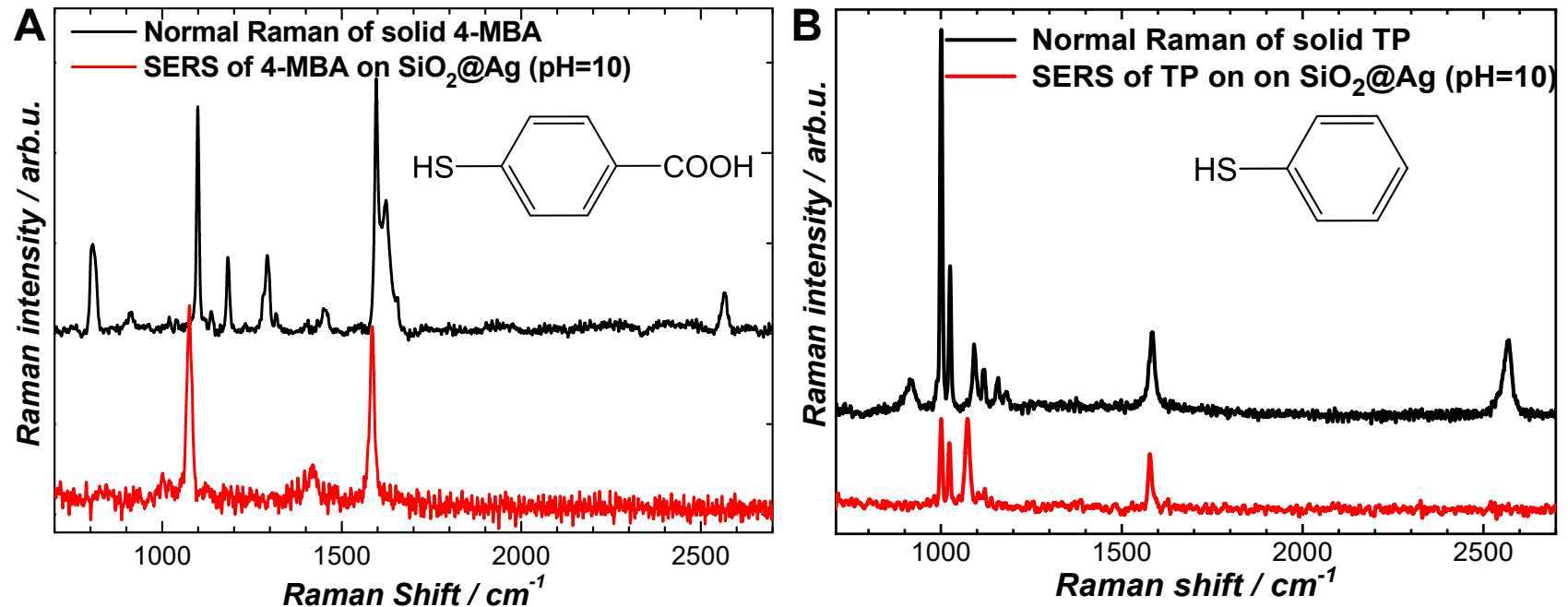

Figure S5. Normal Raman and SERS spectra of (A) 4-MBA and (B) TP. The normal Raman spectra were collected from solid films of the compounds at an excitation power of $5 \mathrm{~mW}$ and with a spectral integration time of $30 \mathrm{~s}$. The SERS spectra were collected from individual 4-MBA- or TP-coated $\mathrm{SiO}_{2} @ \mathrm{Ag} \mathrm{SNPs}$ in an aqueous environment at $\mathrm{pH}$ of 10 at an excitation power of $2.6 \mathrm{~mW}$ with a spectral integration time of $1 \mathrm{~s}$. The molecular structures of the 4-MBA and TP were shown as the insets in panels A and B, respectively. The peaks in the wavenumber range of $2500-2600 \mathrm{~cm}^{-1}$ in the normal Raman spectra were assigned to the S-H stretching modes, which completely disappeared in the SERS spectra, indicating that both 4-MBA and TP were chemisorbed on Ag surfaces through covalent Ag-S interactions. 


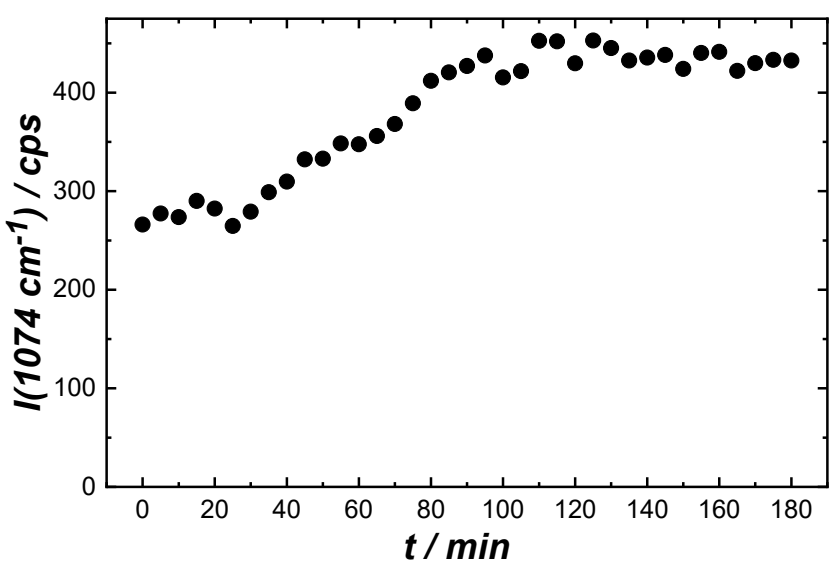

Figure S6. Temporal evolution of the peak intensity at $1074 \mathrm{~cm}^{-1}$ in the time-resolved SERS specta shown in Figure 1D. Time-resolved SERS spectra were collected on one 4-MBA-coated $\mathrm{SiO}_{2} @ \mathrm{Ag} \mathrm{SNP}$ upon exposure to $785 \mathrm{~nm}$ laser illumination at $\mathrm{pH}$ of 10 (in $1.0 \mathrm{mM} \mathrm{K}_{2} \mathrm{CO}_{3}$ ). The spectral acquisition time was 5 $\mathrm{s}$, and the laser power was $1.1 \mathrm{~mW}$.
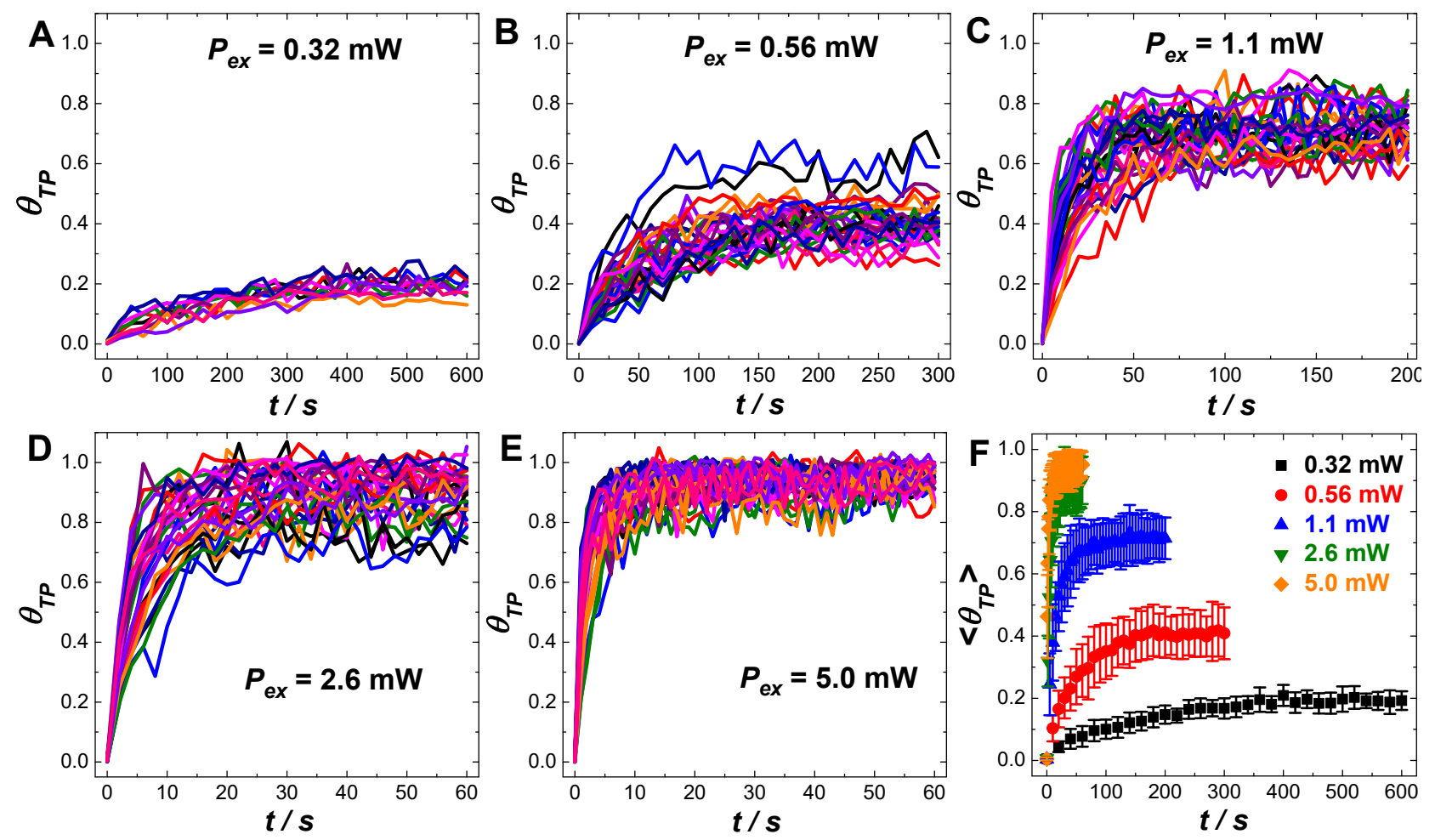

Figure S7. Temproal evolution of $\theta_{T P}$ on individual 4-MBA-coated $\mathrm{SiO}_{2} @ \mathrm{Ag} \mathrm{SNPs}$ at various excitation laser powers of (A) 0.32, (B) 0.56, (C) 1.1, (D) 2.6, and (E) $5.0 \mathrm{~mW}$. Each $\theta_{T P}$ trajectory represented the kinetic results collected from on one individual 4-MBA-coated $\mathrm{SiO}_{2} @ \mathrm{Ag} \mathrm{SNP}$ under each specific reaction condition. (F) Temporal evolution of ensemble-averaged $\theta_{T P}\left(<\theta_{T P}>\right.$ ) at various excitation powers. The error bars represent the standard deviations among different particles at each excitation power. In all these experiments, the $\mathrm{pH}$ of surrounding solution was kept at 10 . The spectral acquisition time was $20 \mathrm{~s}$ for 0.32 $\mathrm{mW}, 10 \mathrm{~s}$ for $0.56 \mathrm{~mW}, 5 \mathrm{~s}$ for $1.1 \mathrm{~mW}, 2 \mathrm{~s}$ for $2.6 \mathrm{~mW}$, and $1 \mathrm{~s}$ for $5.0 \mathrm{~mW}$, respectively. 

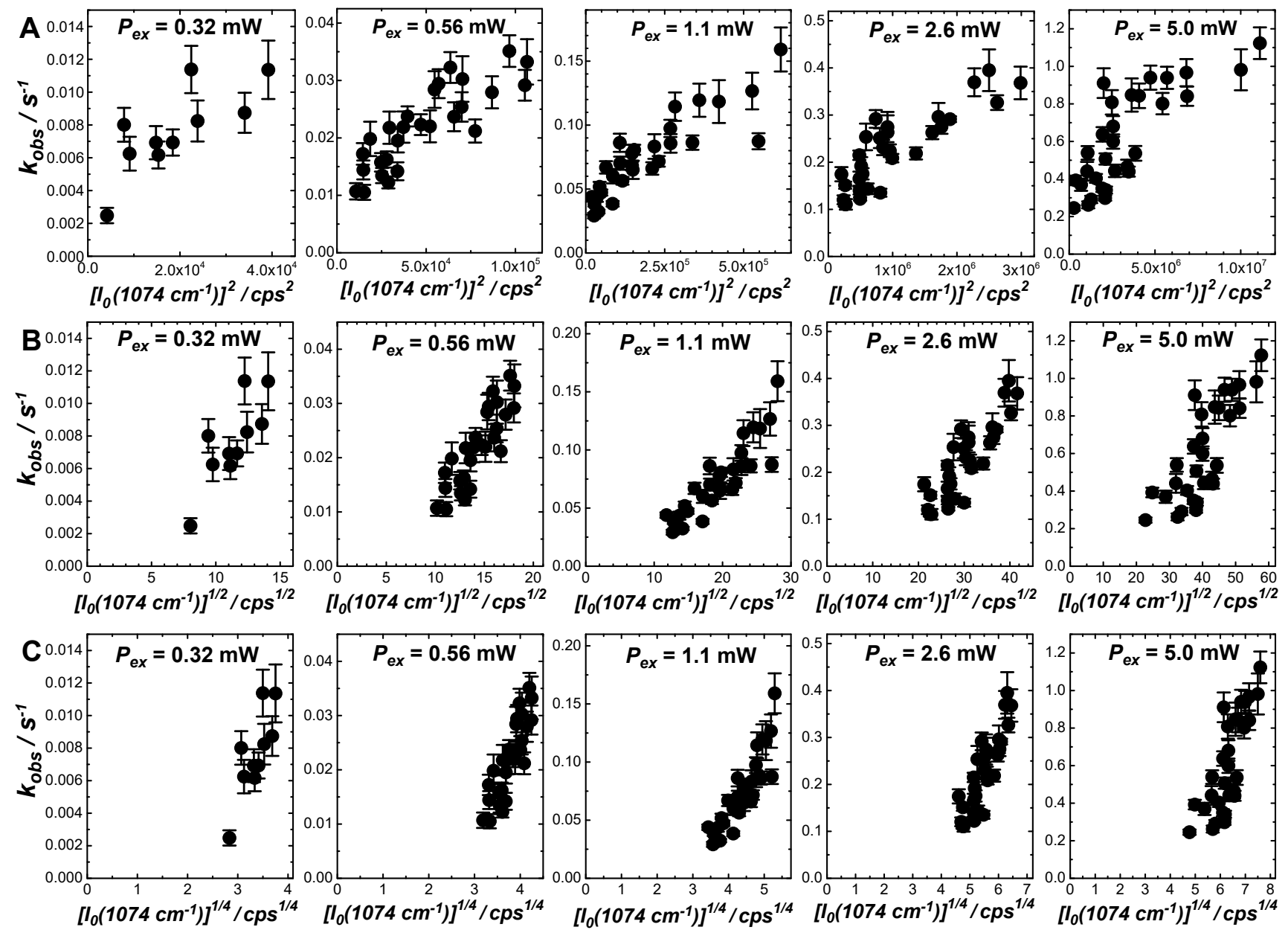

Figure S8. (A) Plots of $k_{\text {obs }} v s$. the square of the initial peak intensities of the $v(\mathrm{CS})$ mode, $\left[I_{0}\left(1074 \mathrm{~cm}^{-1}\right)\right]^{2}$. (B) Plots of $k_{o b s} v s$. the square root of the initial peak intensities of the $v(\mathrm{CS})$ mode, $\left[I_{0}\left(1074 \mathrm{~cm}^{-1}\right)\right]^{1 / 2}$. (C) Plots of $k_{o b s} v s$. the fourth root of the initial peak intensities of the $v(\mathrm{CS})$ mode, $\left[I_{0}\left(1074 \mathrm{~cm}^{-1}\right)\right]^{1 / 4}$. The kinetics measurements were conducted at five different $P_{e x}$ values $(0.32,0.56,1.1,2.6$, and $5.0 \mathrm{~mW})$, while the excitation wavelgnth, $\lambda_{\text {ex }}$, was fixed at $785 \mathrm{~nm}$. In all experiments, the $\mathrm{pH}$ was maintained at 10 . The spectral acquisition time was $20 \mathrm{~s}$ for $0.32 \mathrm{~mW}, 10 \mathrm{~s}$ for $0.56 \mathrm{~mW}, 5 \mathrm{~s}$ for $1.1 \mathrm{~mW}, 2 \mathrm{~s}$ for $2.6 \mathrm{~mW}$, and $1 \mathrm{~s}$ for $5.0 \mathrm{~mW}$, respectively. At each $P_{e x}$, the time-resolved SERS results were collected on different individual $\mathrm{SiO}_{2} @ \mathrm{Ag}$ SNPs one-particle-at-a-time. 


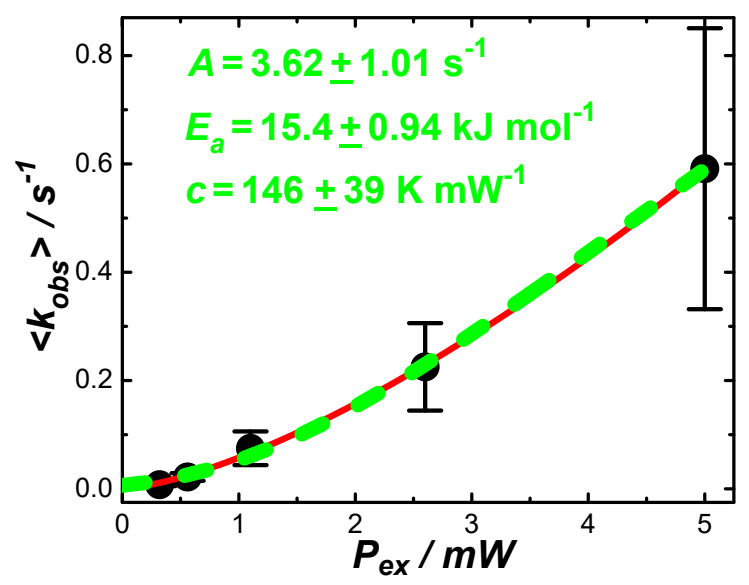

Figure S9. Power-dependence of ensemble-averaged $k_{\text {obs. }}$. The green dash curve showed the results when fitting the experimental data with the Arrhenius-type temperature dependence (Eqn. 9) for a photothermal reaction. For comparison, the curve fitting result using the power function (Eqn. 8) for hot carrier-driven photochemistry was shown as the solid red curve.

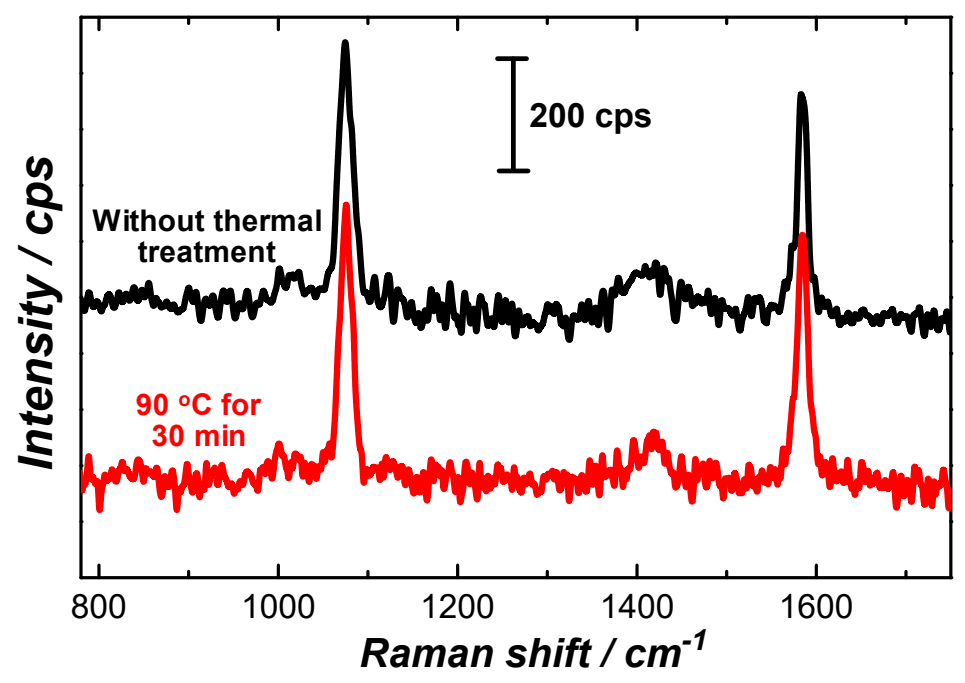

Figure S10. Representative SERS spectra of 4-MBA collected on individual $\mathrm{SiO}_{2} @ \mathrm{Ag} \mathrm{SNPs}$ at pH of 10 (black) without and (red) with thermal heating treatment at $90^{\circ} \mathrm{C}$ for $30 \mathrm{~min}$. The SERS spectra were collected at room temperature with an $P_{\text {ex }}$ of $1.1 \mathrm{~mW}$ and a spectral integration time of $5 \mathrm{~s}$. 

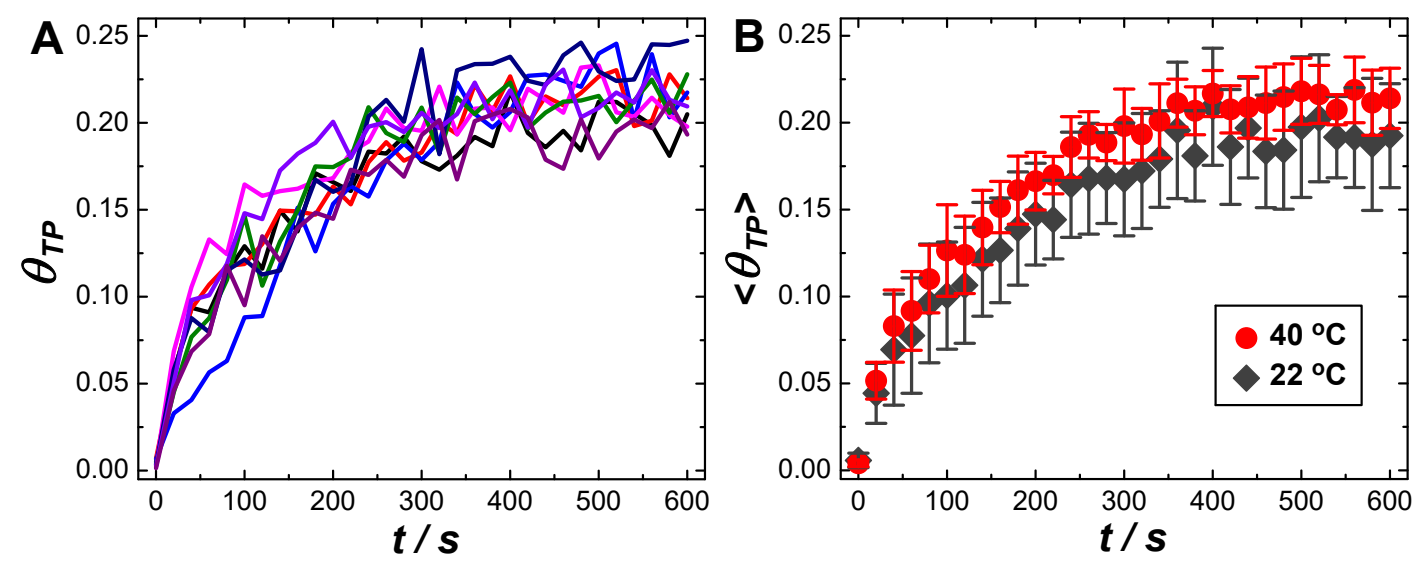

Figure S11. (A) Temporal evolution of $\theta_{T P}$ on individual 4-MBA-coated $\mathrm{SiO}_{2} @ \mathrm{Ag} \mathrm{SNPs}$ in water $\left(\lambda_{\mathrm{ex}}=\right.$ $785 \mathrm{~nm} ; P_{\mathrm{ex}}=0.32 \mathrm{~mW}$ ) at a reaction temperature of $40^{\circ} \mathrm{C}$. (B) Ensemble averaged $\theta_{T P}$ trajectories at room temperature $\left(22^{\circ} \mathrm{C}\right)$ and at a bulk reaction temperature of $40^{\circ} \mathrm{C}$. The SERS spectra were collected at $P_{\text {ex }}$ of $0.32 \mathrm{~mW}$ and a spectral integration time of $20 \mathrm{~s}$.
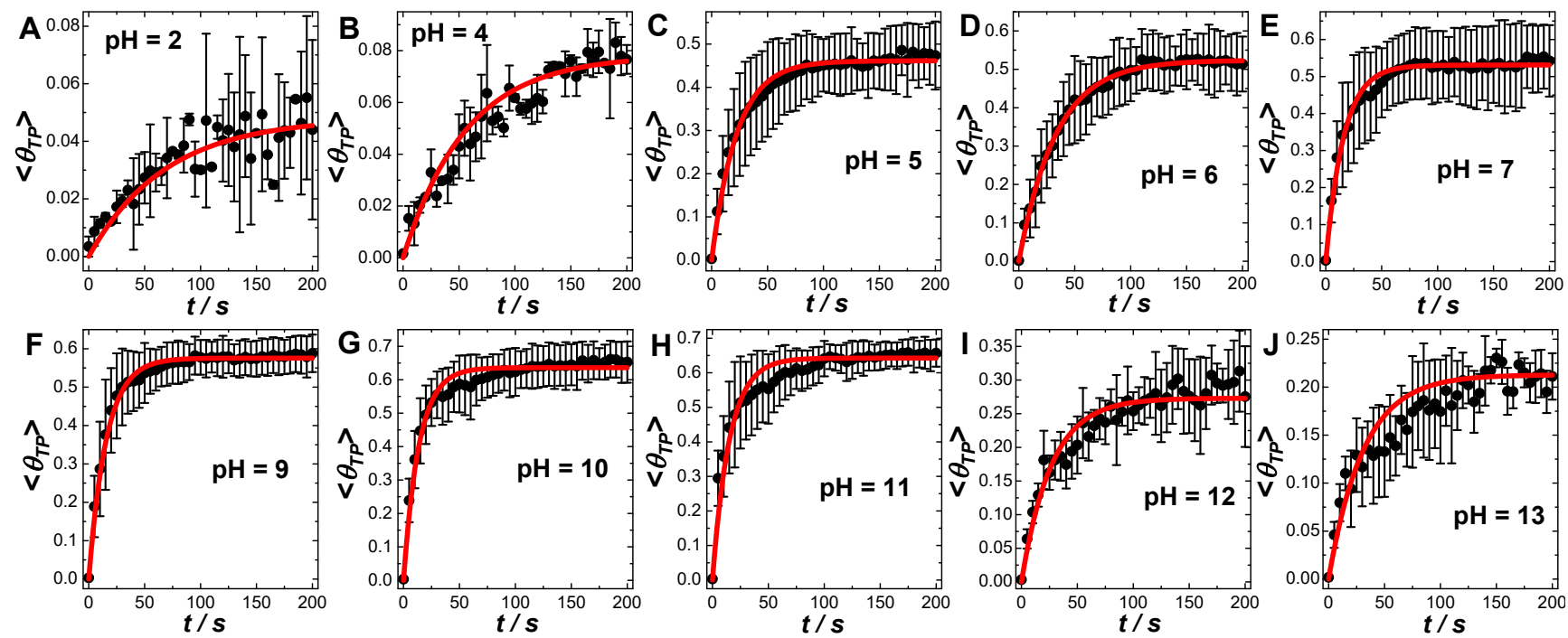

Figure S12. Temperoal evolution of ensemble averaged $\theta_{T P}\left(<\theta_{T P}>\right)$ during photocatalytic reactions $\left(\lambda_{\mathrm{ex}}=\right.$ $785 \mathrm{~nm} ; P_{e x}=1.1 \mathrm{~mW}$ ) at different $\mathrm{pH}$ values of (A) 2, (B) 4, (C) 5, (D) 6, (E) 7, (F) 9, (G) 10, (H) 11, (I) 12 , and $(\mathrm{J}) 13$. The $\mathrm{pHs}$ of the reaction medium were adjusted by mixing appropriate amounts of $\mathrm{HCl}$ and $\mathrm{NaOH}$ in the absence of $\mathrm{K}_{2} \mathrm{CO}_{3}$. At each $\mathrm{pH}$, the SERS-based kinetic measurements were conducted on 10 different 4-MBA-coated $\mathrm{SiO}_{2} @ \mathrm{Ag}$ SNPs. The error bars represented the standard deviations among the $\theta_{T P}$ trajectories collected form 10 different $\mathrm{SiO}_{2} @ \mathrm{Ag} \mathrm{SNPs}$ at each $\mathrm{pH}$. The $<\theta_{T P}>$ trajcetories were fitted with a first-order rate law and the curve fitting results were shown as a red curve in each panel. 

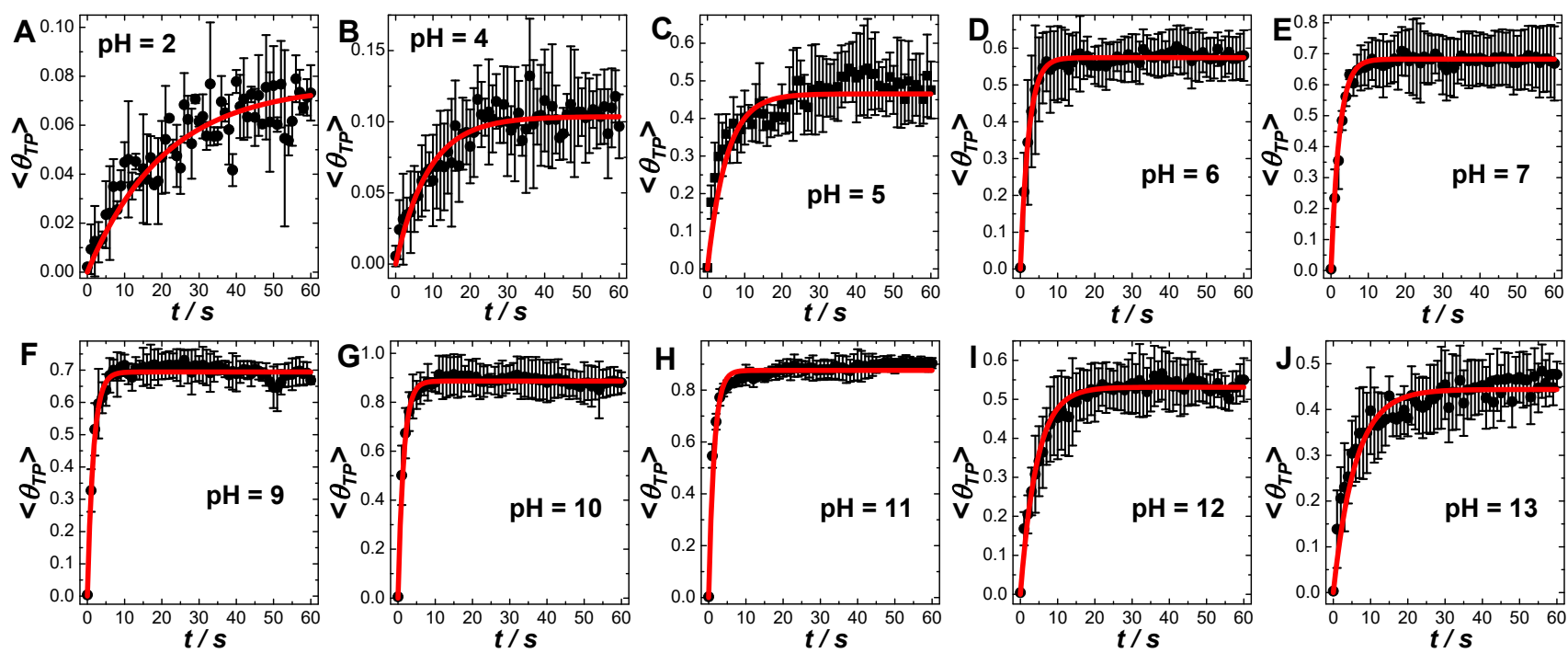

Figure S13. Temperoal evolution of ensemble averaged $\theta_{T P}\left(<\theta_{T P}>\right)$ during photocatalytic reactions $\left(\lambda_{\mathrm{ex}}=\right.$ $785 \mathrm{~nm} ; P_{e x}=5.0 \mathrm{~mW}$ ) at different pH values of (A) 2, (B) 4, (C) 5, (D) 6, (E) 7, (F) 9, (G) 10, (H) 11, (I) 12 , and $(\mathrm{J}) 13$. The $\mathrm{pHs}$ of the reaction medium were adjusted by mixing appropriate amounts of $\mathrm{HCl}$ and $\mathrm{NaOH}$ in the absence of $\mathrm{K}_{2} \mathrm{CO}_{3}$. At each $\mathrm{pH}$, the SERS-based kinetic measurements were conducted on 10 different 4-MBA-coated $\mathrm{SiO}_{2} @ \mathrm{Ag}$ SNPs. The error bars represented the standard deviations among the $\theta_{T P}$ trajectories collected form 10 different $\mathrm{SiO}_{2} @ \mathrm{Ag} \mathrm{SNPs}$ at each $\mathrm{pH}$. The $<\theta_{T P}>$ trajcetories were fitted with a first-order rate law and the curve fitting results were shown as a red curve in each panel.

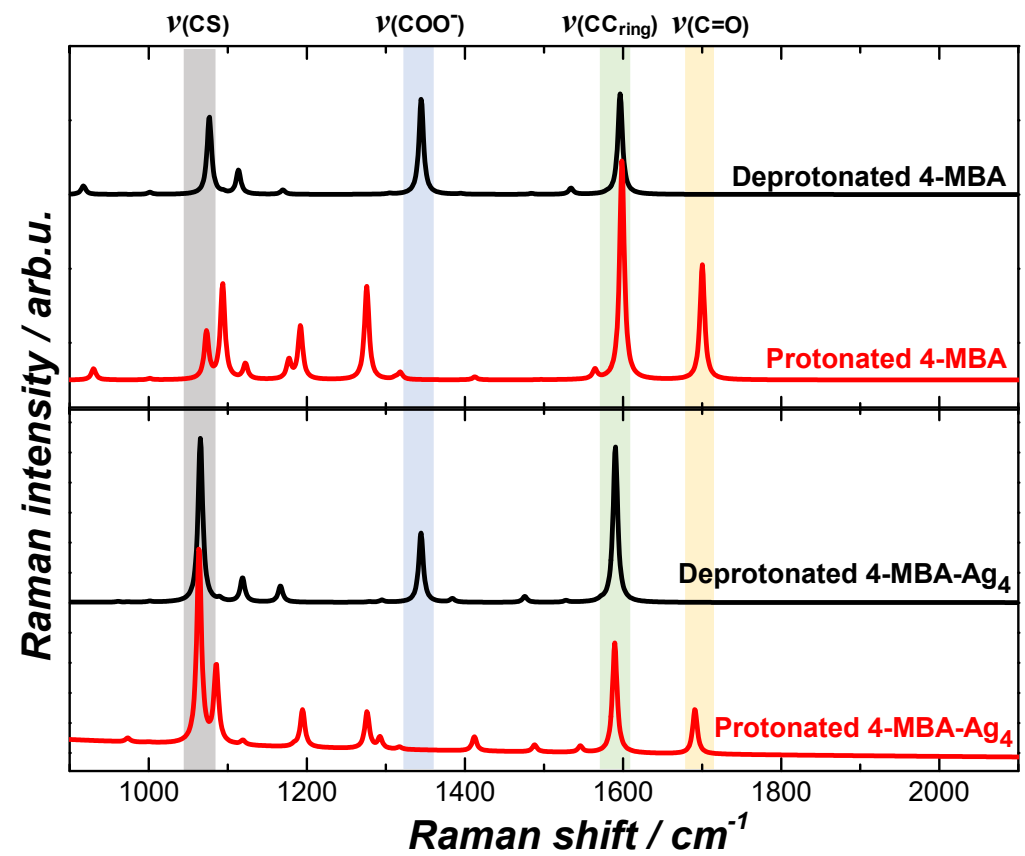

Figure S14. DFT-calculated Raman spectra of deprotonated 4-MBA, protonated 4-MBA, deprotonated 4MBA- $\mathrm{Ag}_{4}$, and protonated 4-MBA- $\mathrm{Ag}_{4}$. The Raman modes of $v(\mathrm{CS}), v\left(\mathrm{COO}^{-}\right), v\left(\mathrm{CC}_{\text {ring }}\right)$, and $v(\mathrm{C}=\mathrm{O})$ were highlighted. 


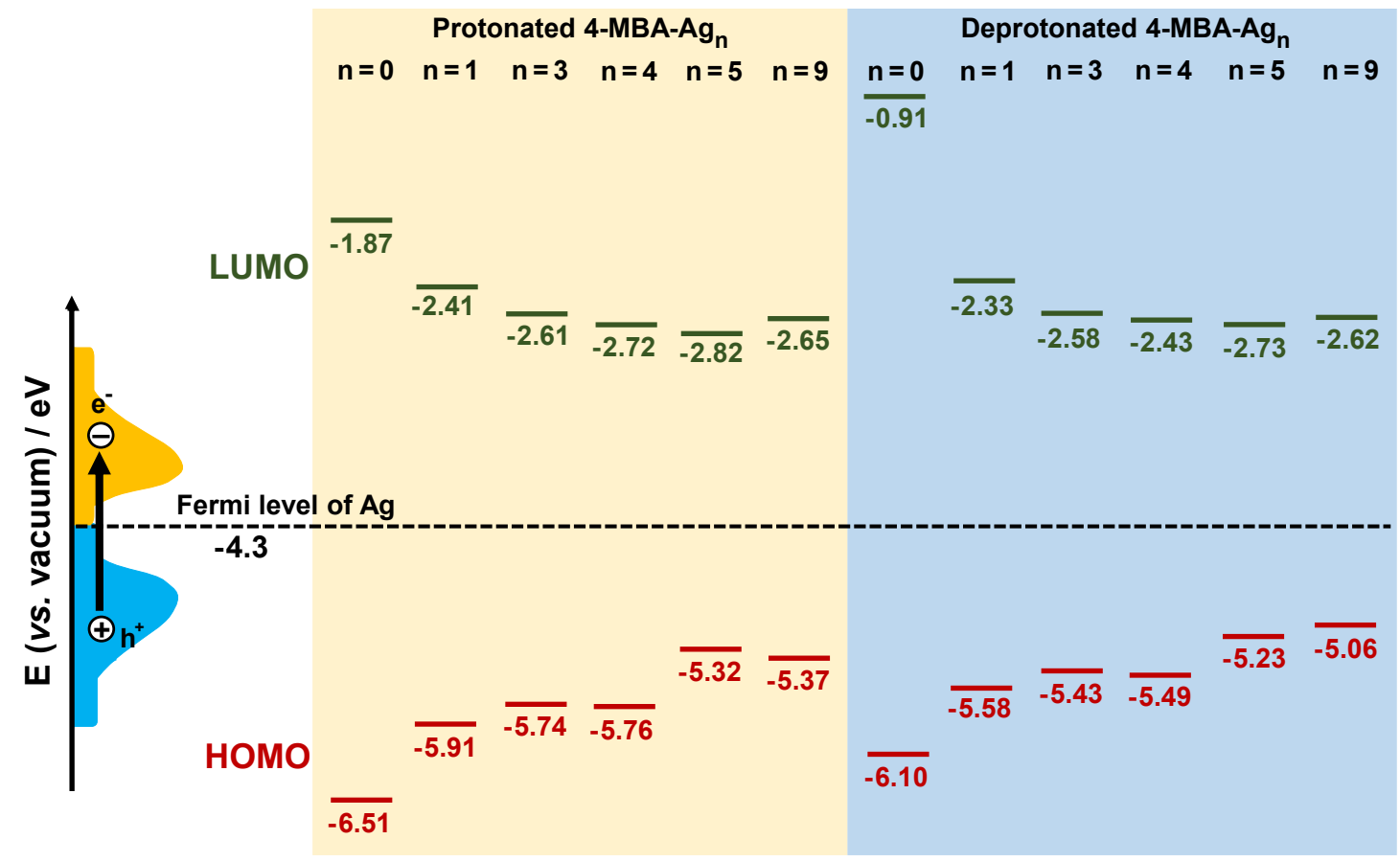

Figure S15. DFT-calcualted energy levels of the LUMO and HOMO of 4-MBA and 4-MBA chemisorbed to $\mathrm{Ag}_{\mathrm{n}}$ atomic clusters ( $\mathrm{n}$ refers to the number of $\mathrm{Ag}$ atoms in the clusters) in the protonated and deprotonated forms. The energy diagram was plotted using an energy scale of electron volts $(\mathrm{eV})$ and the vacuum level as the reference.

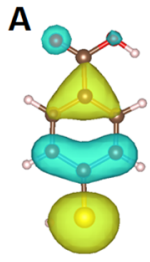

Protonated 4-MBA

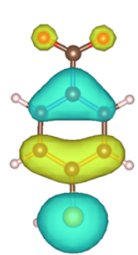

Deprotonated

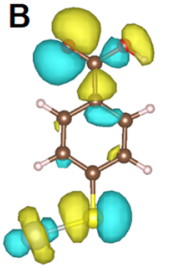

Protonated 4-MBA-Ag 1
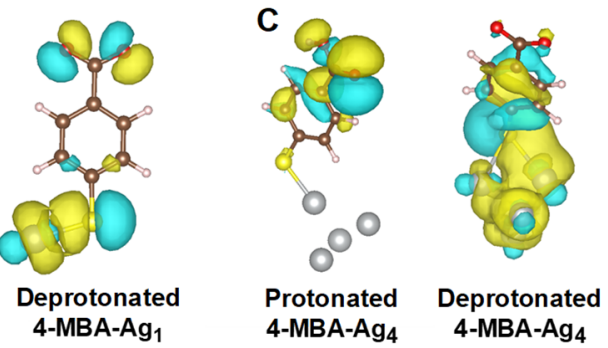

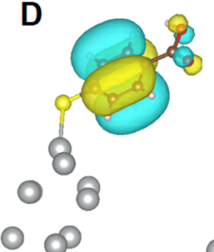

Protonated 4-MBA-Ag9

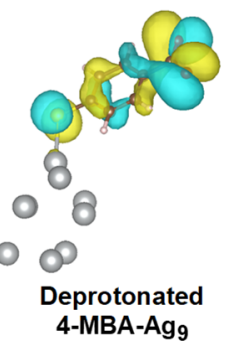

Figure S16. Optimized geometries and electron density maps of the HOMO orbitals of (A) 4-MBA and 4MBA chemisorbed to (B) an $\mathrm{Ag}$ atom, (C) an $\mathrm{Ag}_{4}$ cluster, and (D) an $\mathrm{Ag}_{9}$ cluster in the protonated and deprotonated forms. 


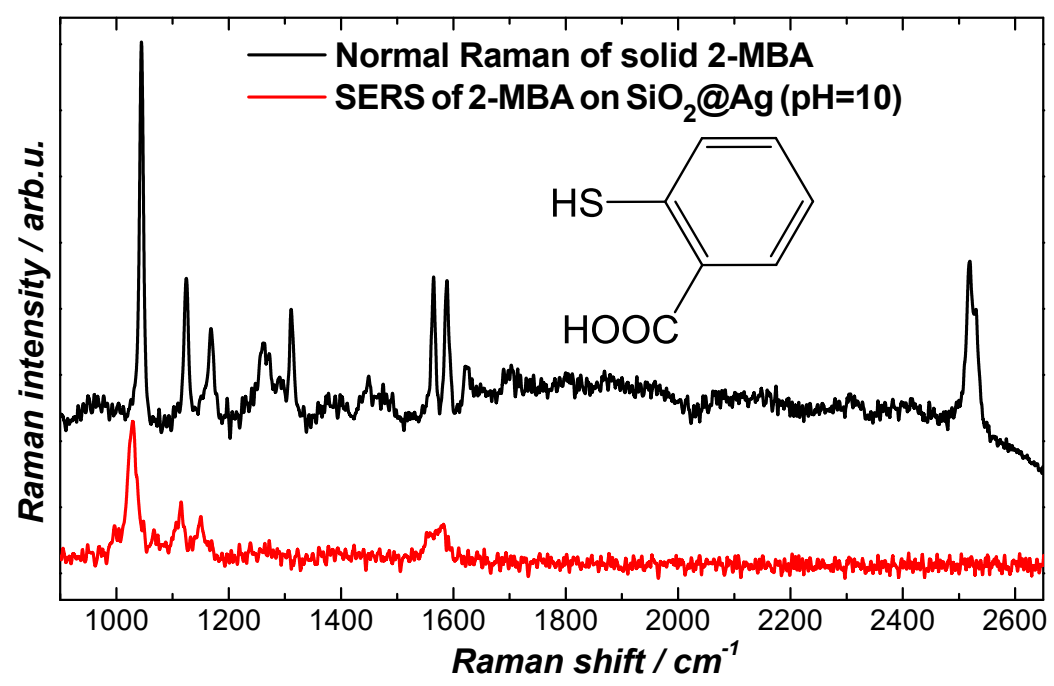

Figure S17. Normal Raman and SERS spectra of 2-MBA. The normal Raman spectrum was collected from a solid 2-MBA film at an excitation power of $5.0 \mathrm{~mW}$ and with a spectral integration time of $30 \mathrm{~s}$. The SERS spectrum was collected from an individual 2-MBA-coated $\mathrm{SiO}_{2} @ \mathrm{Ag}$ SNP in an aqueous environment at pH of 10 at an excitation power of $2.6 \mathrm{~mW}$ with a spectral integration time of $1 \mathrm{~s}$. The molecular structure of 2MBA is shown as the inset. The peak centered around $2530 \mathrm{~cm}^{-1}$ in the normal Raman spectrum was assigned to the S-H stretching mode, which completely disappeared in the SERS spectrum, indicating that 2-MBA was chemisorbed on Ag surfaces through covalent Ag-S interactions.
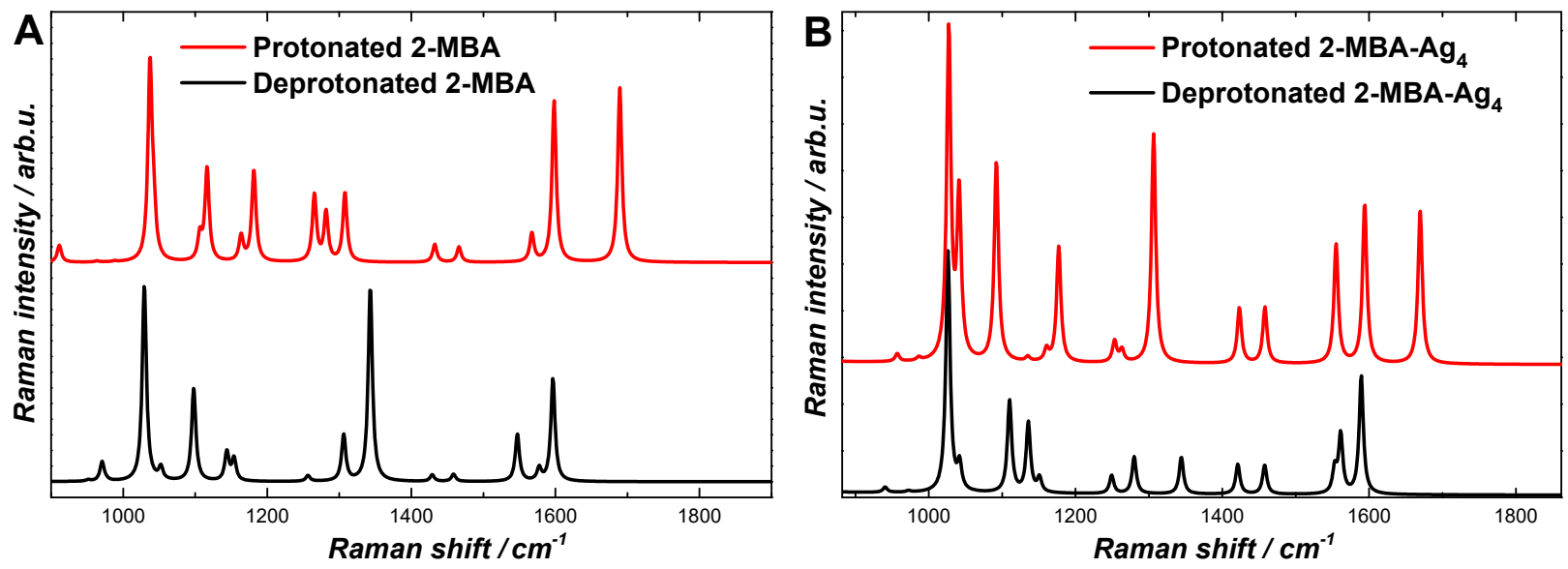

Figure S18. (A) Calculated Raman spectra of deprotonated and protonated 2-MBA. (B) Calculated Raman spectra of deprotonated and protonated 2-MBA- $\mathrm{Ag}_{4}$. 

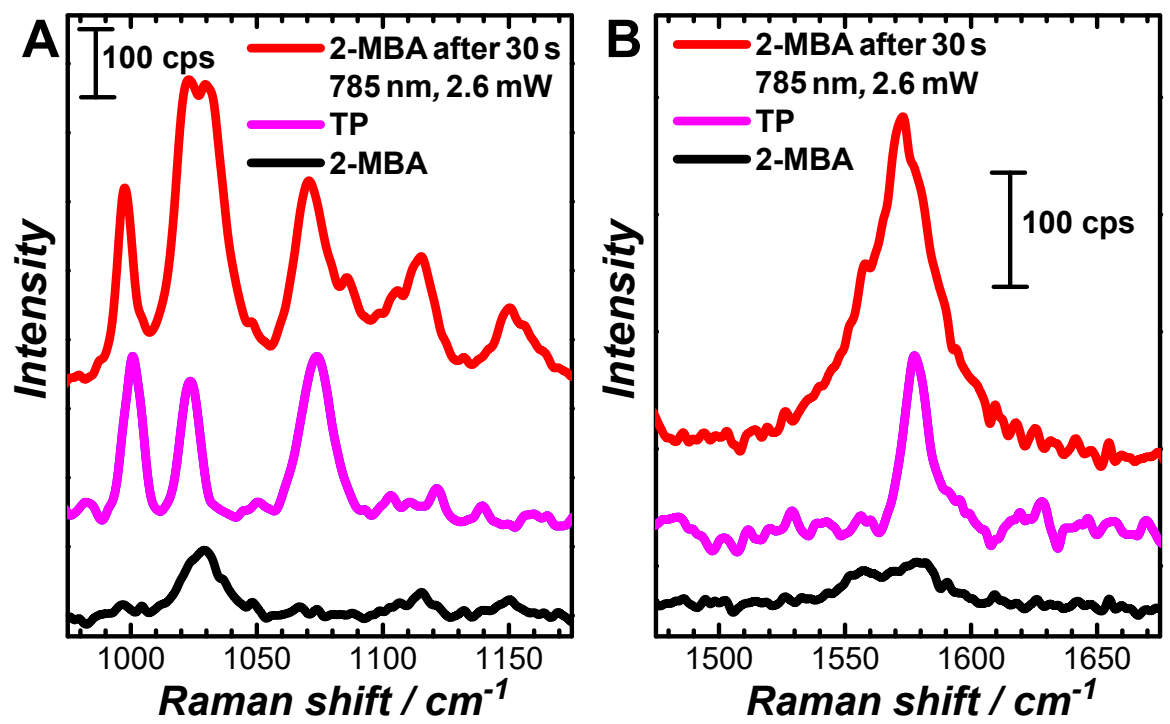

Figure S19. SERS spectra of (black) 2-MBA and (magenta) TP adsorbed on the surfaces of $\mathrm{SiO}_{2} @ \mathrm{Ag} \mathrm{SNPs}$ in the wavenumber ranges of (A) $975-1175 \mathrm{~cm}^{-1}$ and (B) $1475-1675 \mathrm{~cm}^{-1}$. The red spectrum was collected from a 2-MBA-coated $\mathrm{SiO}_{2} @ \mathrm{Ag} \mathrm{SNP}$ in $1.0 \mathrm{mM} \mathrm{K} \mathrm{CO}_{3}$ after continuous laser illumination (785 nm, 2.6 $\mathrm{mW}$ ) for $30 \mathrm{~s}$.

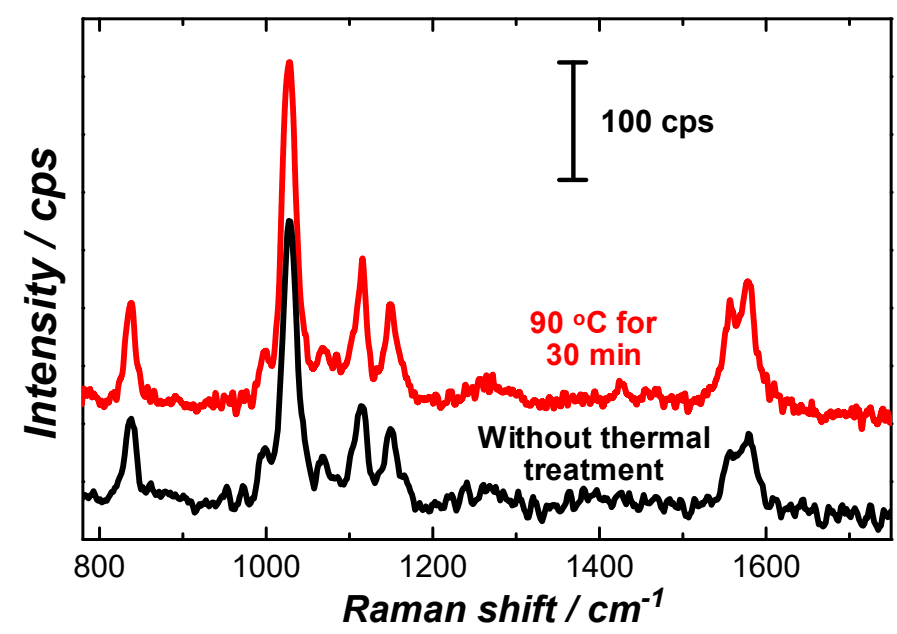

Figure S20. Representative SERS spectra of 2-MBA collected on individual $\mathrm{SiO}_{2} @ \mathrm{Ag} \mathrm{SNPs}$ at pH of 10 (black) without and (red) after thermal heating treatment at $90^{\circ} \mathrm{C}$ for $30 \mathrm{~min}$. The SERS spectra were collected at room temperature with an $P_{\text {ex }}$ of $2.6 \mathrm{~mW}$ and a spectral integration time of $1 \mathrm{~s}$. 

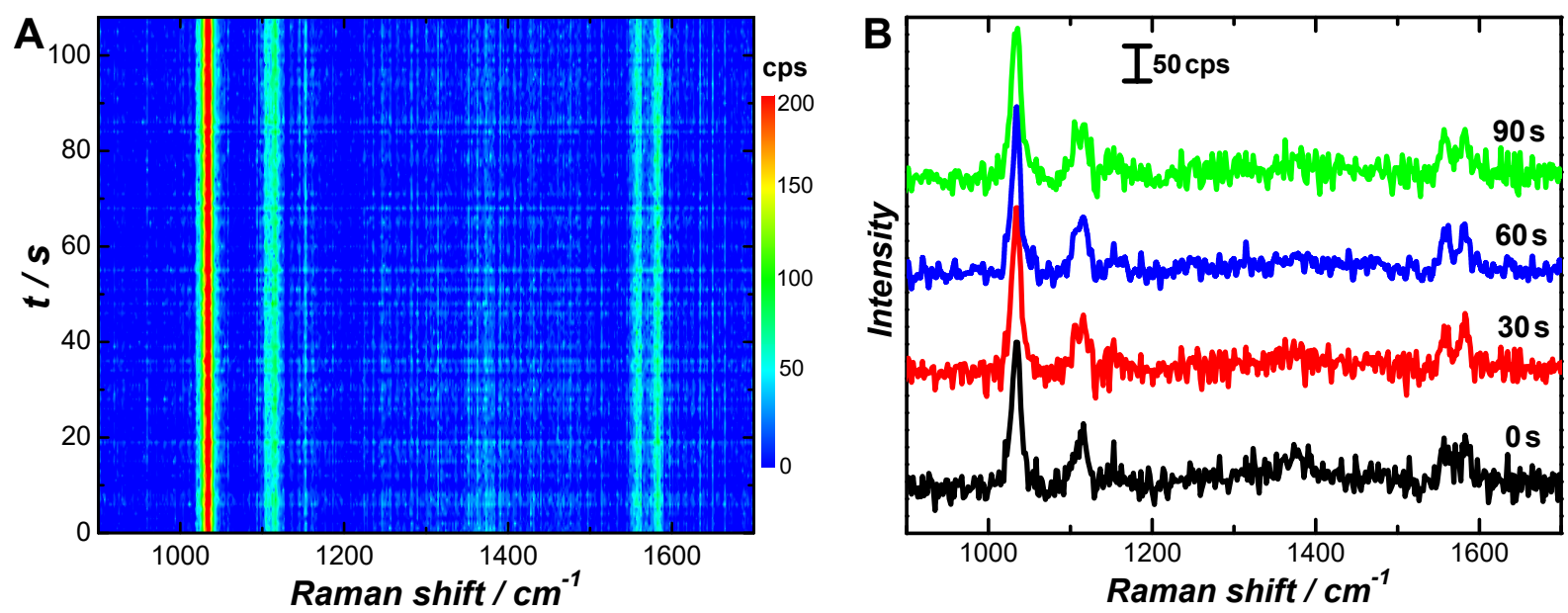

Figure S21. (A) Time-resolved SERS spectra collected on one 2-MBA-coated $\mathrm{SiO}_{2} @ \mathrm{Ag} \mathrm{SNP}$ upon exposure to $785 \mathrm{~nm}$ laser illumination at $\mathrm{pH}$ of 2 . The spectral acquisition time was $1 \mathrm{~s}$, and the laser power was $2.6 \mathrm{~mW}$. (B) Snapshot SERS spectra at reaction times of 0, 30, 60, and $90 \mathrm{~s}$.

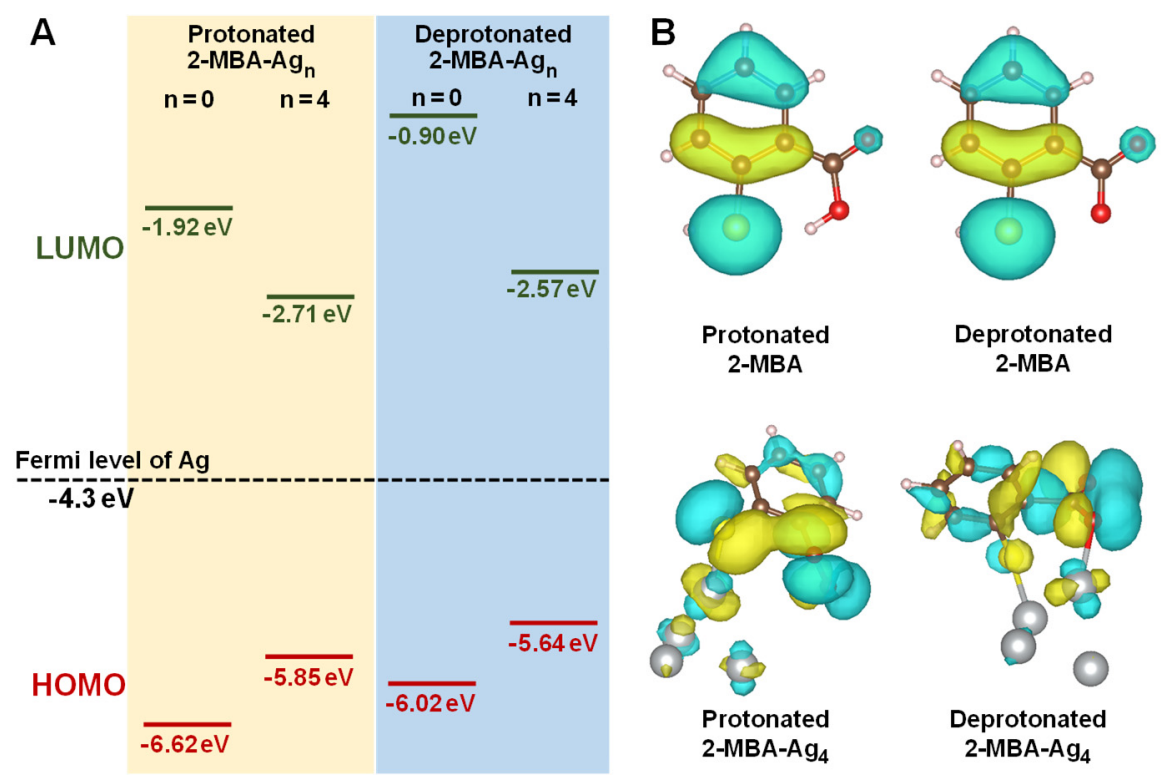

Figure S22. (A) DFT-calcualted energy levels of the LUMO and HOMO of 2-MBA and 2-MBA-Ag 4 in the protonated and deprotonated forms. The energy diagram was plotted using an energy scale of electron volts $(\mathrm{eV})$ and the vacuum level as the reference. (B) Optimized geometries and electron density maps of the $\mathrm{HOMO}$ orbitals of 2-MBA and 2-MBA- $\mathrm{Ag}_{4}$ in the protonated and deprotonated forms. 


\section{S3. References for Supporting Information}

1. Xia, X. H.; Zeng, J.; Oetjen, L. K.; Li, Q. G.; Xia, Y. N. Quantitative Analysis of the Role Played by Poly(vinylpyrrolidone) in Seed-Mediated Growth of Ag Nanocrystals. J. Am. Chem. Soc. 2012, 134 (3), 1793-1801.

2. Zheng, T. T.; Zhang, Q. F.; Feng, S.; Zhu, J. J.; Wang, Q.; Wang, H. Robust Nonenzymatic Hybrid Nanoelectrocatalysts for Signal Amplification toward Ultrasensitive Electrochemical Cytosensing. J. Am. Chem. Soc. 2014, 136 (6), 2288-2291.

3. Zhang, Q. F.; Wang, H. Mechanistic Insights on Plasmon-Driven Photocatalytic Oxidative Coupling of Thiophenol Derivatives: Evidence for Steady-State Photoactivated Oxygen. J. Phys. Chem. C 2018, 122 (10), 5686-5697.

4. Malynych, S.; Luzinov, I.; Chumanov, G. Poly(vinylpyridine) as a Universal Surface Modifier for Immobilization of Nanoparticles. J. Phys. Chem. B 2002, 106 (6), 1280-1285.

5. Wang, H.; Halas, N. J. Mesoscopic Au "Meatball" Particles. Adv. Mater. 2008, 20 (4), 820-825.

6. Zhang, Q. F.; Large, N.; Nordlander, P.; Wang, H. Porous Au Nanoparticles with Tunable Plasmon Resonances and Intense Field Enhancements for Single-Particle SERS. J. Phys. Chem. Lett. 2014, 5 (2), 370-374. 